\title{
Entre dragas y trasmallos: minería mecanizada y cambios en las actividades de pesca en comunidades negras de la cuenca media del río Atrato, Chocó, Colombia ${ }^{1}$
}

\section{Between dredgers and gillnets: Mechanized mining and changes in fishing activities in the black communities of the middle basin of the River Atrato, Chocó, Colombia}

\author{
Wilmar Alexánder Cano López²
}

La subienda va el desde 25 de diciembre hasta mayo. Antes, en la subienda, el pescado se podía coger hasta con tazas en la orilla. ;Había mucho pescado!... Pero ahora no (Pescador, San José de la Calle, 27 de julio de 2017).

\section{Resumen}

Desde la Colonia, el río Atrato ha permitido el poblamiento de sus riberas, se ha constituido en la principal vía de comunicación, y ha sido la fuente de sustento diario para las comunidades negras. Actualmente, la pesca es una actividad prioritaria para estas comunidades pues de ella derivan su sustento diario, alimento y comercio. Sin embargo, la cuenca del Atrato está sufriendo impactos ambientales, la reducción de volúmenes, tallas, y especies de peces. A partir del conocimiento local de los pescadores, este escrito intenta reconstruir algunos elementos clave para comprender los cambios que están sufriendo tanto los procesos ecológicos de la cuenca del Atrato como las dinámicas socioculturales de las comunidades negras. Se argumenta que existe una relación entre los cambios ocurridos en los sistemas de producción-extracción e introducción de nuevas técnicas de captura y los impactos que estas actividades generan en la reducción de poblaciones ícticas.

Palabras clave: Comunidades negras, Minería, Pesca, Río Atrato, Trasmallo.

\begin{abstract}
Since the Colony, Atrato River has allowed the settlement of its banks, has become the main means of communication, and has been the source of livelihood for the black communities. Currently, the fishing is a priority activity for these communities
\end{abstract}

\footnotetext{
Este artículo es resultado parcial del proyecto de investigación: "Cambios en la estructura social de la caza y la pesca y su impacto en la biodiversidad en comunidades negras e indígenas del Chocó Biogeográfico (Atratoy Baudó)", financiado y desarrollado por el Instituto de Investigación Ambientales del Pacífico John von Neumann (IIAP), Quibdó, Colombia, durante el año 2017.

Egresado de Filosofía, magíster en Historia y estudiante de doctorado en Ciencias Sociales, Universidad de Antioquia. Miembro del Grupo de Investigación Medio Ambiente y Sociedad (MASO), Universidad de Antioquia, Medellín, Colombia. e-mail: wilmar.cano@udea.edu.co
} 


\section{Bioetnia Volumen 14, 2017}

because their livelihood, food and trade is derived from this activity. However, the basin of Atrato is suffering environmental impacts, the reduction of volumes, sizes, and species of fish Based on the local knowledge of fishermen, this article attempts to reconstruct some of the key elements for undergoing both the ecological processes of the Atrato basin and the sociocultural dynamics of the black communities. It is argued that there is a relationship between the changes occurred in production-extraction systems and introduction of new techniques for capture and the impacts that these activities generate in the reduction of fish stocks.

Keywords: Atrato river, Black communities, Fishing, Mining, Trasmallo.

\section{Introducción}

Innumerables comunidades rurales, negras e indígenas, han utilizado las actividades de caza y pesca como forma de sustento a través de toda la historia. La fauna y los peces han servido a estas comunidades como fuente de alimento y proteína, empleo y elementos de intercambio socioeconómico y cultural. Sobre la base de estas actividades, las comunidades han construido dinámicas socioculturales complejas en torno a los aspectos simbólicos, técnicos, alimentarios y económicos en el marco de grupos humanos específicos.

Los recursos de bosques y aguas (océanos y ríos) parecían ilimitados. No obstante, la contaminación mundial de agua y el aire, la implementación de técnicas más lesivas, el crecimiento demográfico y el aumento de demanda sobre recursos de bosques y aguas, y el tipo de capturas (que no respetan períodos de desove y tamaño de la captura en el caso de la pesca, o el sexo, la edad o los períodos de gestación en el caso de la caza), han creado fuertes presiones sobre los ecosistemas de bosques, océanos y ríos en todo el mundo. La disminución de fauna, desaparición de especies específicas de peces, y la reducción de capturas, no sólo significa un impacto a nivel ambiental y en procesos ecológicos, sino que este panorama implica consecuencias en la seguridad alimentaria, estado nutricional y bienestar socioeconómico de miles de personas pertenecientes a comunidades negras, indígenas, rurales o locales que viven de actividades de caza y pesca.

La pérdida de los principales recursos naturales (forestales, pesqueros e hídricos) en todo el mundo se ha convertido en uno de los principales problemas, por este motivo en la actualidad la intervención sobre los sistemas de producción, explotación o extracción, como la pesca o la caza, es una prioridad en todas las agendas de académicos, políticos y tomadores de decisiones en búsqueda de la mitigación o eliminación de impactos antrópicos sobre los recursos (Defeo 2015). Sin embargo, se ha evidenciado que estas medidas, estrategias y acciones tienen un carácter fundamentalmente reactivo, marginal y poco efectivo en la gestión de ecosistemas, servicios ecosistémicos y recursos naturales (Andrade 2007).

Las comunidades negras del medio Atrato chocoano están percibiendo cambios drásticos en la actividad de la pesca, en lo que respecta a disminución de volumen y calidad de los peces, así como reducción y desaparición de especies. Esta situación es delicada porque las prácticas de pesca constituyen formas de sustento, alimentación y comercio para ellos. A partir del conocimiento local de los pescadores, este artículo intenta reconstruir algunos elementos clave para comprender los cambios que están sufriendo tanto los procesos ecológicos de la cuenca del Atrato como las dinámicas socioculturales de las comunidades negras. Se argumenta que existe una relación entre los cambios ocurridos en los sistemas de producción-extracción e introducción de nuevas técnicas de captura y los impactos que estas actividades generan en la reducción de poblaciones ícticas. 


\section{Metodología}

La selección de metodologías para la investigación estuvo determinada por el componente sociocultural del proyecto. En este sentido, la etnografía practicada por el equipo fue la herramienta de recolección de información cualitativa y la base interpretativa. El trabajo de campo fue central para confrontar las fuentes secundarias con las prácticas socioculturales y económicas, así como las concepciones sobre la pesca que tienen los actores. Por medio de la observación directa y entrevistas semiestructuradas se pudo caracterizar los actores sociales involucrados en las actividades de la pesca, y a sus dinámicas socioculturales y económicas. Se recogieron discursos sobre las practicas artesanales, tradicionales y posibles conflictos con otras prácticas modernas o tecnificadas, usos del suelo, relaciones con el territorio y con los demás actores, así como percepciones sobre los impactos ambientales de las prácticas productivas y estrategias o recomendaciones para enfrentar el problema. Asimismo, se realizaron talleres con las comunidades (líneas de tiempo, cartografías, grupos focales) con el fin de conocer las representaciones del espacio por parte de los actores. De esta manera, el método etnográfico permitió visibilizar factores como la percepción cultural sobre el ambiente, la economía local, la biodiversidad, el uso de la tierra y de las fuentes hídricas, las características sociales de los grupos y los tipos de organización social que allí se generan (Agreda 2005, Hernández 1971).

El proyecto realizó dos trabajos de campo entre julio y octubre de 2017 en comunidades del Medio Atrato y el Baudó. En el Atrato participaron seis comunidades (Isla de los Palacios, SanAlejandro, San José de la Calle, Buchadó, Palos Blancos y Beté); la selección de estas comunidades obedeció: 1) a la relación histórica que tenían con la pesca, 2) la presencia predominante de pescadores en las comunidades, en donde la pesca constituye la principal actividad económica o de sustento diario, 3) comunidades negras, pertenecientes al mismo consejo comunitario de COCOMACIA (Consejo Comunitario Mayor de la Asociación Campesina Integral del Atrato).

Área de estudio. En Chocó existen tres hoyas hidrográficas de importancia, a saber: la hoya del Atrato, la hoya del San Juan, y la del Baudó. La hoya del Atrato es la más importante por su tamaño. La alta humedad, las continuas precipitaciones de lluvias anuales y la gran cantidad de ríos (150) y arroyos (350) que recogen y nutren el cauce del río Atrato, lo convierten en uno de los más caudalosos del mundo (Gutiérrez et al. 2011, p.104). Debido a que más de 65.000 hectáreas de su cuenca media permanecen inundadas durante más de la mitad del año, este río se considera vital para la producción, cultivo y captura de peces, y en este sentido, fundamental para la seguridad alimentaria de miles de personas en comunidades pescadoras y municipios cercanos, así como abastecedor de pescados a otras regiones del país (Lagarejo 2015).

La lentitud de su corriente se explica porque su hoya es baja y de poco declive, lo que permite la formación de pantanos y ciénagas, y favorece su continuo desbordamiento (Gutiérrez et al. 2011, p. 105, Lasso et al. 2011). Las ciénagas del Atrato son claves no sólo por su importancia socioeconómica, sino también para el control de crecidas e inundaciones del río que afectan las poblaciones ribereñas y los espacios destinados para actividades agropecuarias (Lagarejo 2015). Las ciénagas son los ecosistemas predominantes de la cuenca del Atrato, por lo que las comunidades han construido una cultura, identidad y vínculo con estas, de manera que se preocupan, intervienen y gestionan continuamente el destino, aprovechamiento, manejo y conservación de estos cuerpos de agua (Gutiérrez et al. 2011, p. 106).

Como lo plantean Ayala $(2003,2004)$ y Gutiérrez et al. (2011), los sistemas tradiciones de producción de las comunidades étnicas (agricultura, caza, pesca, minería y explotación forestal) están 


\section{Bioetnia Volumen 14, 2017}

estrechamente vinculados con las oferta natural y ambiental de la cuenca delAtrato. Sin embargo, la relación de las comunidades (negros, indígenas, mestizos y colonos) no se puede concebir únicamente en términos de usufructo, aprovechamiento y explotación de especies y recursos naturales, sino que existe toda una construcción sociocultural, étnica y productiva atravesada por un entorno ambiental y territorial complejo (Gutiérrez et al. 2011, p. 104). El río permite, configura y regula las redes de comunicación e intercambio, así como fortalece los vínculos sociales y culturales de las poblaciones ribereñas.

No obstante, esta relación sociocultural, étnica y económica de aprovechamiento y uso de los recursos, hace inevitable que las comunidades modifiquen, impacten o transformen los ecosistemas de la cuenca (Ayala 2004, IIAP 2008). En efecto, el río Atrato está afectado ampliamente por actividades antrópicas que tienen como consecuencia impactos ambientales en toda la cuenca. En la parte alta, la explotación de oro y platino, el vertimiento de desechos municipales, la deforestación y la desecación de ciénagas son fenómenos de carácter expansivo y generalizables a toda la cuenca (Lasso et al. 2011). También hay un deterioro evidente de las condiciones de navegabilidad, debido a la deforestación irracional en las cabeceras de los ríos, la sedimentación, los sólidos en suspensión y un dragado insuficiente que han hecho que el lecho del río esté perdiendo profundidad y calidad de agua (Lagarejo 2015, Alcaldía Municipal del Atrato 2003).

Caracterización histórica del Atrato. Desde el período colonial, en el Chocó todos los intereses económicos y relaciones de comercio se establecieron en relación con la extracción y comercio de oro. La actividad minera se configuró como centralidad de todos los procesos económicos y sociales, relacionados con la explotación de minas y el poblamiento afrodescendiente (West 1972, p. 45). Como las minas de aluvión se encontraban en riberas, lechos y antiguos meandros de ríos o arroyos, la geografía de los ríos del Chocó fue clave para el poblamiento de la región, pues los afrodescendientes establecieron asentamientos en lugares próximos a minas y placeres auríferos, con la intención de aprovechar la riqueza aurífera y los recursos del río (Cano 2015). El poblamiento chocoano ha sido ribereño (De la Torre 2015, Restrepo 1992, Cano 2015), caracterizado por la dispersión, como se puede apreciar en la Figura 1. Este tipo de poblamiento ribereño y disperso constituyó una estrategia de resistencia, porque manumisos, cimarrones y grupos de familias afrodescendientes se refugiaron en riberas alejadas, donde pudieran minear y cultivar parcelas para su subsistencia, tratando de huir de los centros poblados constituidos como formas de control (Leal 2008, p. 413). Así que, por una parte, factores de tipo material, y por otra, factores de tipo sociopolítico, determinaron el poblamiento disperso del Chocó.

Con la abolición de la esclavitud entre los siglos XIX y XX, ocurrió un tipo de poblamiento negro y mulato de tipo ribereño un poco más consistente, caracterizado por el interés de las comunidades en practicar actividades económicas de subsistencia como la minería y la pesca, pero de manera independiente. Asílo plantea Mosquera (1992, p. 164):

Ocurrió en la cuenca del Pacífico una prolongada colonización minera independiente de batea (mazamorreo) llevada a cabo por esclavos manumitidos, desertando de los antiguos reales de minas. Su presencia territorial, muy visible hacia finales del siglo XIX, impactaba a varios afluentes orientales de los ríos Atrato y San Juan... (Figura 1).

El río es el elemento fundamental de este poblamiento. La conformación espacial del río configura la estructura del asentamiento afrodescendiente en la ribera (Figura 2). De esta manera, hay varios imperativos climáticos y vitales que se

\section{4}




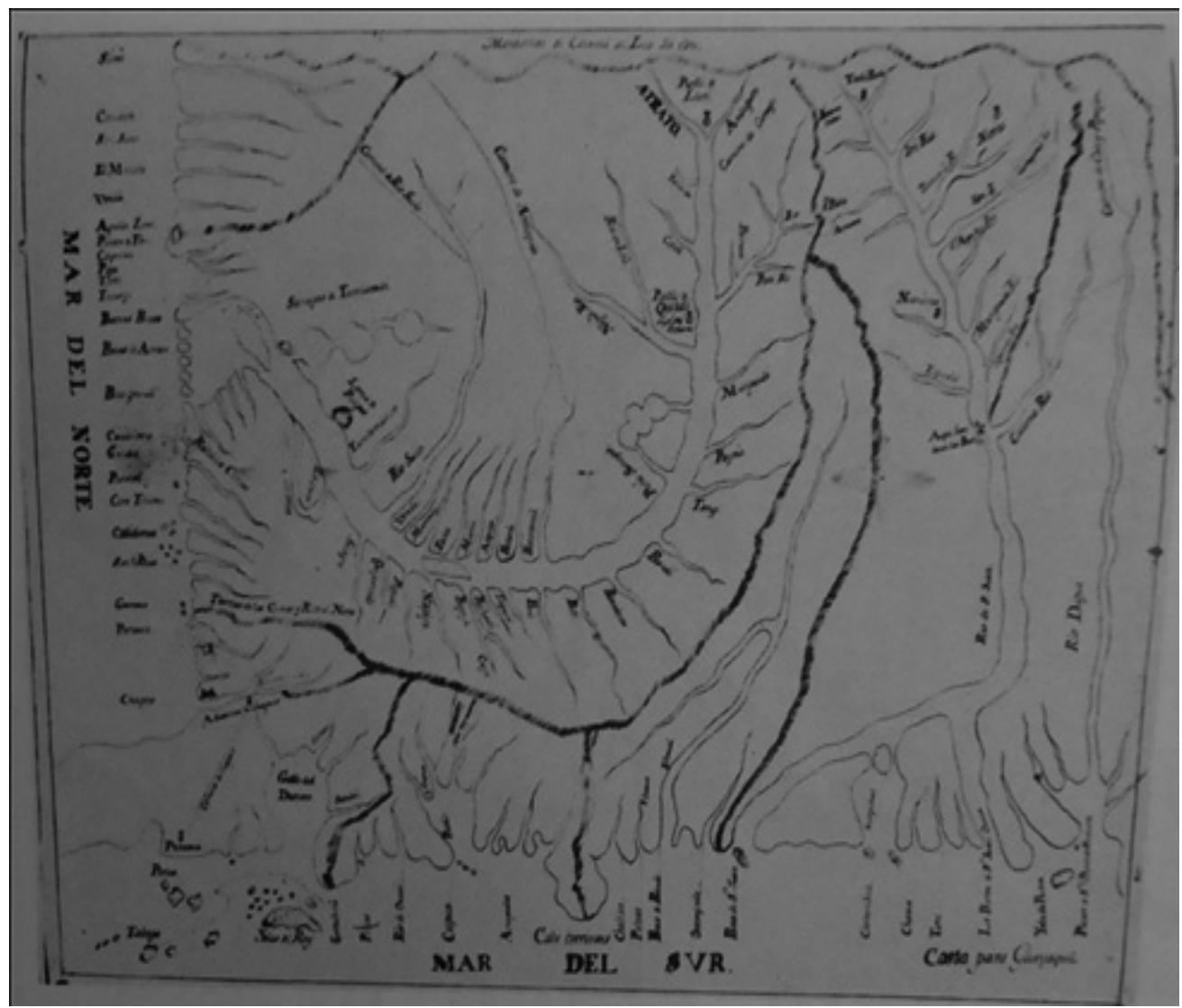

Figura 1. Ríos del Chocó, siglo XVIII.

Fuente: tomado de Cano 2015

suplen conformando un asentamiento ribereño; por una parte, se asegura el acceso al complemento nutricional que brinda la pesca y la obtención de minerales (Mosquera 1992, p. 168), también la constitución de espacios para cultivos de plátano, arroz, entre otros, constituyen una estrategia de pancoger para suplir o complementar la alimentación del habitante ribereño, y por otra, el contacto directo con el río asegura el transporte para el intercambio comercial y cultural aldeano o con otras poblaciones (Contraloría 1943). El río es la vida misma del pueblo. No hay otra manera, el camino es el río (Gómez 1997, p. 21).

No solo las comunidades étnicas del Chocó han tenido interés en los ríos. Debido a las características geográficas y geológicas del Chocó, los yacimientos de metales de oro y platino han estado durante siglos bajo las dinámicas de arrastre y

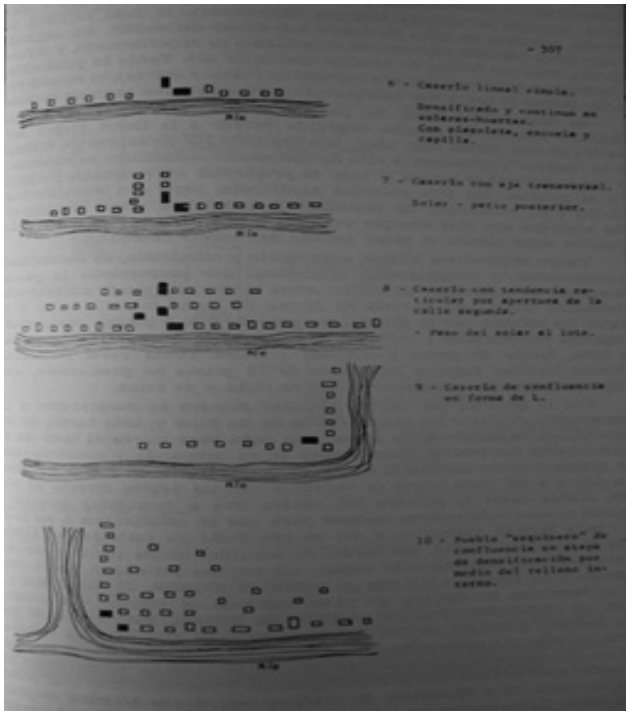

Figura 2. Esquema de poblamiento ribereño en Chocó.

Fuente: tomado de Cano 2015 


\section{Bioetnia Volumen 14, 2017}

lavado de los metales, razón por la cual los lechos de los ríos son riquísimos en estos minerales. Así pues, los gobiernos vieron en la extracción minera, una estrategia rentable para el crecimiento del Estado. Funcionarios, ingenieros y geólogos incentivaron la inversión extranjera y la extracción de recursos por parte de individuos y compañías extranjeras mediante tecnología mecanizada en el Chocó desde la década de 1850 (Cano 2015).

Debido a que la minería con dragas implicaba mucho capital y conocimientos más avanzados, los mineros nacionales y el Estado no tuvieron la capacidad para ingresar al negocio (Álvarez 1952). De modo que fue imperativo permitir la participación de compañías mineras extranjeras, que por medio de grandes inversiones de capital, compran e importan maquinaria, e implementan las técnicas y conocimientos más avanzados en la industria minera, para extraer mediante dragas todas las riquezas auro-platiníferas de los lechos de ríos del Chocó. Así fue como, finalizando el siglo XIX y comienzos del siglo XX, en el Chocó se presentaron titulaciones de minas a extranjeros y concesiones de minas en lechos de ríos como el Atrato y el San Juan a nombre de compañías mineras extranjeras (Cano 2014, Cano 2015, Leal 2009).

Los contratos de concesión entre el estado y las compañías mineras en la primera década de 1900 estipulaban claramente que el concesionario, con el fin de extraer los metales con procedimientos modernos, podía modificar las conformaciones de ríos, terrenos y ciénagas. Así lo plantea el contrato de concesión del río Iró entre el gobierno nacional y Leopoldo Cajiao:

Dicha explotación tiene por objeto extraer los minerales que se encuentran en el cauce del río Iró, sus orillas y ciénagas. Con tal fin el concesionario podrá valerse de dragas, monitores, buzos o cualquier procedimiento apropiado, o construir canales y cortadas para secar las ciénagas contiguas al río o algunas secciones de su curso actual... (AGN: MinMinas, T. 9: fl. 11).

Lozano (1976), plantea que las operaciones de las dragas habían destruido la riqueza agrícola porque estas tenían que remover enormes cantidades de tierra, por lo que las riberas de los ríos se encontraban desoladas, a pesar de haber sido habitadas tiempo atrás por pequeños mineros. El autor hace hincapié en que aquellos lugares donde antes pasaban los ríos y habitaban mineros, debido a las dragas se encuentran "únicamente con las montañas de piedra que van dejando las dragas al paso de su poder arrasador" (p. 57). Como se verá, actualmente las prácticas de minería mecanizada continúan afectando las riberas, los lechos, las ciénagas, los recursos acuáticos y las comunidades ribereñas del Atrato.

Caracterización pesquera del Atrato. En la actualidad, la actividad económica predominante en el medio Atrato es la pesca, la cual se combina con explotación forestal, agricultura y caza. No obstante, estas actividades no son estáticas y resulta a veces difícil establecer prioridades porque ellas dependen o varían de acuerdo con factores ambientales, orden público y condiciones del mercado (IIAP 2008, p. 46). Esta capacidad de complementar o diversificar los sistemas productivos según situaciones, contextos o condiciones, ha sido una parte fundamental de la construcción histórica de las comunidades étnicas a partir de experiencias comunes, que le ha permitido a las comunidades del medio Atrato, no solo posibilitar su subsistencia con un modelo de producción tradicional (De la Torre 2015), sino también legitimar con estas prácticas su etnicidad como pueblos negros o indígenas (Domínguez 2015, Martínez 2013).

El Decreto 1745, reglamentario de la Ley 70 de 1993, establece las funciones administrativas de los consejos y los procedimientos que deben cursar las comunidades negras y consejos comunitarios para la consecución de títulos de tierras colecti- 
vas (Hoffmann 2007, Oslender 2008, Restrepo 2004, República de Colombia 2001, Martínez 2013, Parra 2005, Rodríguez 2005, Oslender 2004, Lemaitre 2011). Las comunidades deben demostrar que son culturalmente diferenciadas, territorialmente establecidas y con prácticas culturales definidas, con el fin de acceder a derechos y otras posibilidades legales que brinda el Estado (Domínguez 2015). Las comunidades deben cumplir tres requisitos fundamentales para obtener estos títulos: 1) organizarse en consejos comunitarios; 2) establecer y demostrar que tienen una cultura propia; y 3) probar que habitan ancestralmente un territorio delimitado y baldío de la nación. De esta manera, se puede comprender por qué dentro de los discursos y procesos de etnización en el Pacífico, el territorio y las prácticas ancestrales-tradicionales adquieren un significado importante. Así lo plantea el Capítulo 1 de la Ley 70 de 1993:

Las actividades y técnicas agrícolas, mineras, de extracción forestal, pecuarias, de caza, pesca y recolección de productos naturales en general, que han utilizado consuetudinariamente las comunidades negras para garantizar la conservación de la vida y el desarrollo autosostenible.

Las comunidades negras aprovechan mayormente el recurso pesquero en las cuencas medias y bajas de los ríos, mientras que las cabeceras de los ríos son el espacio para que las comunidades indígenas realicen capturas (Gutiérrez etal. 2011, p. 133). Esta diferenciación espacial obedece a la conformación histórica de los asentamientos y poblamientos del Chocó. Castrillón (1982) propone una contraposición histórica entre ambas comunidades en las estrategias de conformación de los espacios, pues las comunidades negras fueron desplazando paulatinamente a los indígenas hacia las cabeceras de los ríos y de esta manera aprovechar las tierras que tenían un valor estratégico por el acceso a bosques y ríos, por tratarse de tierras ya labradas y preparadas para el cultivo (Castrillón 1982, p. 187). Actualmente, las especies aprovechadas, así como los métodos o técnicas de pesca utilizados, varían según las condiciones de la cuenca y el tipo de comunidad que practica la pesca.

Gutiérrez et al. (2011, p. 112) plantean que existen alrededor de 1.243 pescadores en el Atrato (18\% de la población está relacionada con actividades de pesca). Se ha estimado que la producción pesquera en las ciénagas del Atrato se aproxima a las 1.600 toneladas al año, es decir unos 30 $\mathrm{kg} / \mathrm{ha} / \mathrm{año}$, de cuyo volumen entre $30 \%$ y $50 \%$ proceden de migraciones de peces desde el bajo Atrato (Gutiérrez et al. 2011, p. 112) (Figura 3). Las especies de pescado con mayor importancia histórica en el Atrato son: el bocachico, el quícharo, el bagre, el dentón y la doncella, capturas que encuentran un mercado amplio y permanente a nivel local y regional (IIAP 2008, p. 177).

Las actividades de pesca son ejercidas todo el año, pero son estacionales en niveles de producción y captura, pues los ciclos más productivos están relacionados con las migraciones de algunas especies de peces, sobre todo cuando hay subienda los primeros meses del año entre diciembre-abril (Gutiérrez et al. 2011, p. 112-4, Lemos 2012, p. 60). Durante la subienda en el Atrato, se da pleno uso de la mano de obra porque la mayoría de los pobladores (pescadores y pescadores potenciales) se trasladan a las orillas, construyen viviendas temporales y emplean todos los aparejos de pesca con el fin de hacer más eficiente la captura (De la Torre 2015, p. 131).

Estos períodos de subienda son claves para la economía familiar, comunitaria y para la seguridad alimentaria de miles de personas que habitan la cuenca del Atrato, porque las comunidades pueden abastecer sus necesidades alimentarias, así como comercializar gran parte de los excedentes, y de esta manera, apoyar también las necesidades de proteínas de otras poblaciones humanas de la 
Bioetnia Volumen 14, 2017

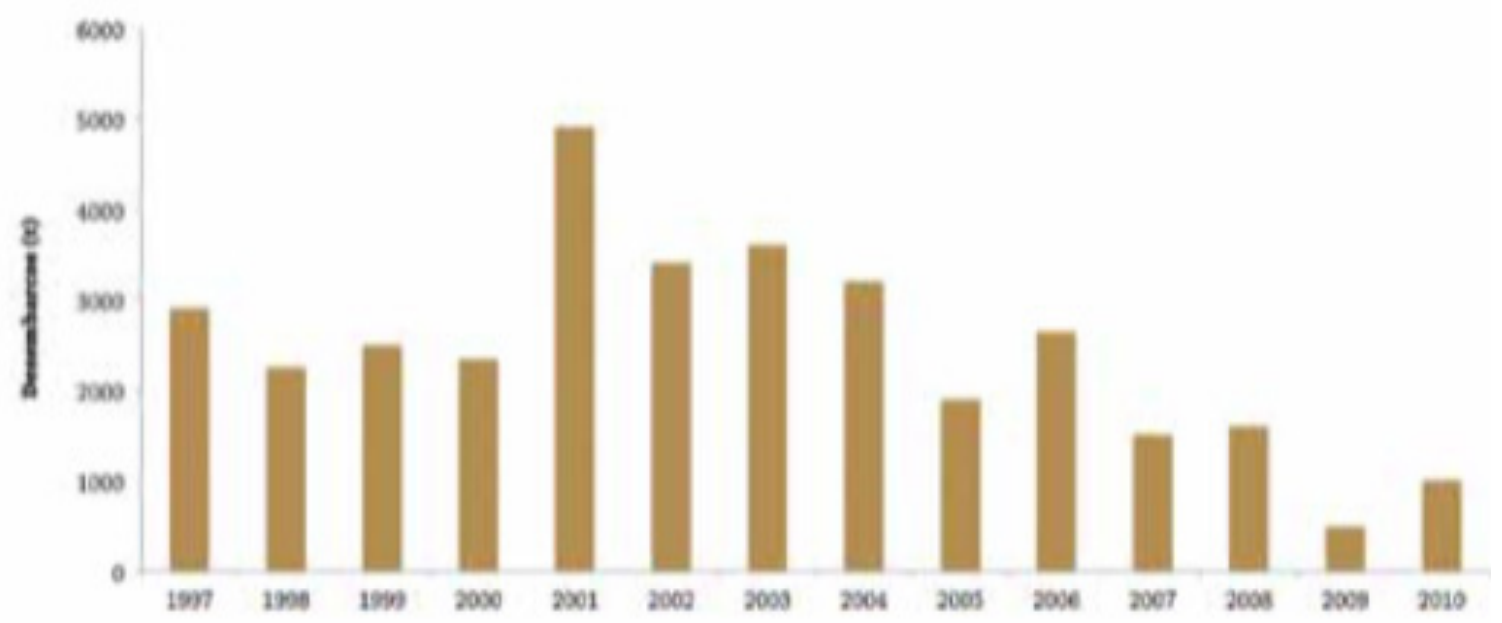

Figura 3. Comparativo de capturas de pescados en Atrato.

Fuente: tomado de Rivas y Gómez 2017

región (Lemos 2012, p. 62).

Aunque todas las personas de la comunidad están involucradas en las actividades de pesca, hay distinciones importantes para comprender las dinámicas sociales. La pesca, en el período de subienda, es una actividad masculina (De la Torre 2015, p. 132, Román 1991, p. 102). Durante la subienda, se pesca entre dos y tres días en cada localidad, donde los hombres comienzan las faenas desde tempranas horas de la mañana, cargan sus canoas o pangas, y llevan el pescado para que mujeres y niños seleccionen, guarden o preparen (cecinen, salen, entre otros) y llevarlo al intermediario. Después de la subienda, la mayor parte del año (entre mayo-diciembre) las faenas se reducen a una por semana (Román 1991).

Actualmente, se percibió esta misma dinámica en las comunidades visitadas. Los hombres van entre una y dos veces al día a revisar los aparejos colocados en sitios estratégicos, y traen el pescado en el bote. Mujeres y niños contribuyen con alimentación para los pescadores y la preparación del pescado (seleccionar, cecinar, almacenar, cocinar). En la cuenca media del Atrato, los niños son introducidos desde temprana edad en las actividades de pesca. También los pescadores aseguran que aprendieron la actividad desde muy jóvenes, entre los 9 o 10 años, cuando salían con sus padres, o los ayudaban en alguna parte de los procesos, como preparar los aparejos, descargar los pescados del bote, o ayudar a las mujeres en su preparación. Después del período de subienda, las comunidades se dedican a otras actividades de subsistencia.

Con respecto al período de subienda y las comunidades que exclusivamente se dedicaban a la pesca en la década de 1990, Román (1991) plantea lo siguiente:

Únicamente en Palo Blanco, San José de la Calle y Ciénaga derivan el sustento de la pesca; en las demás localidades existen diversidad de ocupaciones: agricultura, minería, extracción de madera, lo que les permite efectuar rotación periódica durante el año, atendiendo a la pesca en la subienda (p. 102).

Cambios en la estructura social de caza y pesca. Resulta interesante el contraste que se establece entre la década de 1990 y el presente. En efecto, la subienda continúa siendo un acontecimiento espaciotemporal primordial para todas las comunidades pesqueras del Atrato, pues 
cambia ritmos de trabajo y ocupación de los pescadores y sus familias, modifica las movilidades y los trayectos por el río, constituye un factor de desenvolvimiento económico esencial para las comunidades étnicas, y evento fundamental para contribuir a la seguridad alimentaria de las comunidades locales, así como un aporte a la dieta de otras regiones que consumen proteína de pescado. Sin embargo, el trabajo de campo en algunas localidades de la cuenca media del Atrato evidencia que los pescadores y sus familias perciben un cambio drástico en el evento de la subienda del río. Así plantean dos pescadores de la cuenca media del Atrato sobre la última subienda que recuerdan:

La subienda va desde el 25 de diciembre hasta mayo. Antes en la subienda, el pescado se podía coger hasta con tazas en la orilla. ¡Había mucho pescado!... Pero ahora no. La última subienda que hubo hizo muy poco pescado y chiquito. Parece que el pescado subió hasta donde nunca había subido, pero no apareció bajando (Pescador, San José de la Calle, 27 de julio de 2017).

La última subienda fue en el 2012; logramos coger aproximadamente 20-25 arrobas y unas 60 arrobas en toda la subienda. El bote se llenó con los trasmallos, metimos mucho pescado e incluso botamos pescado. Fue brutal... pero ahora el que más ha cogido son 5 libras (Pescador, Buchadó, 28 de julio de 2017).

Sobre la pregunta de cuándo fue la última subienda que recuerdan, emerge entre los pescadores la imagen de un período signado por buena o enorme cantidad de pescado, pero siempre en contraste (casi inmediato) con un presente en el que el río, los recursos acuáticos y la práctica de la pesca han sufrido cambios drásticos con impactos negativos en la subsistencia de las familias.

Durante los talleres, entrevistas y encuestas en el trabajo de campo, los pescadores y pobladores manifestaron una gran preocupación por el estado actual de la pesca en el río. Su principal preocupación está relacionada con la disminución drástica de la pesca expresado en: 1) reducción de las capturas, 2) disminución de cantidad de peces, 3) reducción de calidad de peces, y 4) mengua o extinción de especies. Los pobladores manifiestan que este fenómeno viene ocurriendo en el Atrato desde hace aproximadamente 10 años.

Resulta diciente que esta situación planteada por las mismas comunidades no sea nueva en la literatura científica. Los estudios de Rivas-Lara y Gómez-Vanega (2017), Lagarejo (2015), De la Torre (2015), Lemos (2012), Maldonado et al. (2006), Gutiérrez et al. (2011), IIAP (2008), Rincón y Rivas (2002), han percibido estos cambios y le han atribuido distintas causalidades, factores, impactos o determinantes. Esta situación está en consonancia también con los llamados de atención, las preocupaciones y las gestiones que han venido adelantando organizaciones como la FAO en torno a la problemática de la contaminación de las aguas, la reducción de capturas, la disminución o extinción de especies, la presión sobre ecosistemas pesqueros, el impacto del cambio de técnicas pesqueras, la emergencia de prácticas ilegales o no controladas de pesca (Avendaño 2006, McGoodwin 2002, Akimichi 2002, Stoffle 2002, Sandoval-Moreno y Hernández-García 2013, FAO 2014). El mayor problema radica en aquí está en juego la seguridad alimentaria de las comunidades locales, étnicas y pesqueras (FAO 1996, Clay 2002, Heidhues et al. 2004, FAO 2002, OSAN 2011, Berkes 2008.

Se tiene así que las mayorías de las amenazas al recurso pesquero se pueden plantear como impactos asociados con el desarrollo, entre las que se destacan transformaciones del hábitat (modificaciones hidrológicas y de planicies inundables), represamiento de ríos e introducción de especies exóticas, así como el incremento de poblaciones humanas y la facilidad de desplazamiento y co- 


\section{Bioetnia Volumen 14, 2017}

mercio, que están generando mayor presión sobre los recursos de la pesca (Valderrama 2011, p. 22). Asimismo, las mismas prácticas procedentes del sector pesquero tienen como consecuencias el aumento de la presión pesquera y el crecimiento de la pesca ilegal (Gutiérrez et al. 2011, p. 30).

Avendaño (2006) plantea que, en el escenario de la globalización, modernización y neoliberalismo, las comunidades pesqueras han sufrido una reducción drástica de sus derechos de acceso a los recursos pesqueros en áreas tradicionales de pesca y zonas costeras. Por su parte, McGoodwin (2002) señala que, pese a la preponderancia de la pesca a pequeña escala, su aporte al suministro de alimentos, y su impacto significativamente menor en el ambiente, esta se encuentra sumamente vulnerable a las amenazas del exterior. El modelo de desarrollo económico mundial ha favorecido enfoques y políticas de pesca en gran escala debido a la eficiencia económica y rendimiento en corto tiempo que esta representa. El acceso a financiación, control de tecnología más productiva, apoyo exterior y subvenciones y prerrogativas gubernamentales ponen en desventaja a las comunidades pesqueras frente a la pesca en gran escala.

También, investigaciones señalan que existe una relación estrecha entre problemáticas ecológicas y cambios de tecnologías o técnicas de pesca. Gajardo y Ther Ríos (2011) sostienen que la modernización de la pesca ha generado no sólo una transformación de las prácticas y los saberes de las comunidades pesqueras, sino también impactos ecológicos significativos debido a la sobreexplotación de especies ocasionada por agentes externos y migrantes que utilizan técnicas pesqueras fuera de norma, lo que ocasiona una disminución de peces o incluso imposibilidad de pesca para las comunidades. La FAO (2012) indica que casi el $30 \%$ de todas las especies se encuentran sobreexplotadas. Stoffle (2002) y Sandoval-Moreno y Hernández-García (2013) plantean igualmente que las principales amenazas ecológicas están relacionadas con la introducción de métodos de pesca indiscriminados (indiferentes a tamaños de captura, períodos y lugares de desove, entre otros) por parte de actores en gran escala, externos o ilegales. Esta situación no solo pone en riesgo, limita o imposibilita el acceso a los medios de subsistencia y la seguridad alimentaria de las comunidades, sino que encarece el conflicto entre pescadores, empresarios y autoridades gubernamentales. Akimichi (2002) señala que el descenso de capturas y la sobreexplotación de especies implica la necesidad de implementar medidas de conservación, como las vedas, áreas de protección, etc., que terminan aún más limitando el acceso de los pescadores y comunidades locales al recurso.

Sobre la pesca en el Atrato, los estudios plantean que el estado de los recursos pesqueros del río, al igual que otros del país, parecen haber llegado a su rendimiento máximo (Gutiérrez et al. 2011, p. 112). Rivas-Lara y Gómez-Vanega (2017) evidencian que los peces como la mojarra en el Atrato, tienen menor tamaño que las mismas especies capturadas en otras cuencas, como Orinoco y Magdalena. Los investigadores atribuyen esta situación a la relación con la ubicación geográfica de las áreas estudiadas, las condiciones ambientales, la selectividad de las artes de pesca utilizadas, la presión de pesca ejercida sobre la especie y el número de individuos colectados.

Los mismos pobladores y pescadores de las comunidades locales de la cuenca media del Atrato reconocen que existe actualmente un cambio drástico en el tamaño y volumen de los peces. Los interlocutores plantean siempre como marco de referencia el pasado, donde las tallas grandes, los inmensos volúmenes de los peces en las subiendas, y la calidad del pescado eran mejores en años anteriores que en el presente. Así lo plantea en la comunidad Isla de los Palacios, en Vigía del Fuerte:

Ahora el pescado sube pequeño y baja 
pequeño. El grande ya se perdió. Ahora no están dejando crecer el pescado, porque siempre está pequeño. Ya no se cogen bocachicos grandes con huevos... Donde hay charcos hondos allá se meten los grandes. Así, cuando hay verano, hay pequeños, pero donde hay profundidad, hay grandes. Este es el problema, porque por la sedimentación, cada vez hay menos profundidad en el río y ciénaga, menos charcos y espacio hondos en estos (27 de julio de 2017).

Esta percepción local del tamaño resulta interesante, primero porque logra evidenciar la problemática de la existencia de pescado pequeño que no ha llegado a desarrollarse. La expresión "no lo dejan crecer" plantea efectivamente la fuerte presión de pesca que existe en el Atrato, y las consecuencias ecosistémicas y ecológicas que están relacionadas con los ciclos de vida de los peces (migración, desove, crecimiento y reproducción). Segundo, la disminución del bocachico, que según las investigaciones del IIAP (2008, p. 177) es probablemente la especie que presenta mayor grado de vulnerabilidad debido a la sobrepesca pues se captura durante todo el año en ciénagas y ríos de la cuenca del Atrato. Tercero, la atribución de causalidad a la profundidad del agua, que se ve afectada por la sedimentación de las ciénagas y ríos. Los niveles bajos de las aguas afectan de forma negativa la actividad pesquera, porque reduce considerablemente la población de peces, a la vez que dificultan la navegabilidad y las dinámicas de las faenas de pesca (Lemos 2012, p. 60).

Finalmente, el problema de la sedimentación de los caños, las ciénagas y los ríos es un asunto delicado. Todas las comunidades locales manifestaron efectivamente esta percepción de la transformación de los lechos de la cuenca. El lodo, el sedimento, las palizadas y los residuos sólidos bajan por el Atrato y se aglutinan y precipitan hacia el lecho del río. Los pobladores señalan que en primera instancia se presenta una disminución de la profundidad del agua, que impide la existencia y aglomeración de peces de buen tamaño: "El pescado grande busca lo hondo, entonces la sedimentación y la sequedad impide pescar grandes" (Pescador, Isla de los Palacios, 27 de julio de 2017). Y segundo, esta situación cambia la composición del agua, haciéndola más turbia y menos saludable o agradable para los peces. Algunos pescadores señalan que hay especies como la boquiancha que le gusta el agua clara:

La boquiancha subía dos veces al año, a esta le gusta el agua clara, por eso iba a los caños. Ahora ha desaparecido porque no le gusta esa agua más sucia y débil (Palo Blanco, 29 de julio de 2017).

Al respecto, los estudios señalan varias causas antrópicas que han afectado la producción pesquera en el Atrato: la intensa explotación forestal, las actividades mineras mecanizadas y semimecanizadas en las parte alta y media del Atrato que vierten sedimentos y químicos como el mercurio a las aguas, la sedimentación que limita la producción de oxígeno para los peces, las prácticas de pesca (sobreexplotación, pesca indiscriminada según tamaño, sexo y ciclo de los peces que no deja que ellos adquieran madurez y cumplan procesos reproductivos y de crecimiento), pesca ilegal y cambio de técnicas pesqueras (usos de aparejos lesivos o indiscriminados o uso de tóxicos) y el vertimiento de todo tipo de desechos municipales e industriales a los ríos y ciénagas de la cuenca del Atrato que contaminan las aguas y disminuyen las poblaciones ícticas (Rivas-Lara y Gómez-Vanega 2017, p. 15, Gutiérrez et al. 2011, p. 112, IIAP 2008, p. 24).

Impacto de la minería en la pesca en el Atrato. En el trabajo de campo realizado en algunas comunidades negras de la cuenca media del Atrato, los pobladores, pescadores y participantes en las charlas y entrevistas manifestaron abiertamente 


\section{Bioetnia Volumen 14, 2017}

que la primera causa de la problemática -la caída de las capturas, la reducción de volumen y extinción de especies, así como la sedimentación de las ciénagas- son las actividades mineras que se desarrollan en las partes altas de la cuenca del Atrato. Todas las comunidades visitadas afirman que el origen de la problemática es la minería mecanizada con dragas y dragones que se lleva a cabo en los ríos como el Quito y el Murindó. Así lo plantea un pescador de la población de Palo Blanco:

El pueblo siempre ha sido muy pequeño y el 95\% se dedicaba a la pesca, y ni la madera se tocaba, pero desde hace 10 años, desde el inicio de la minería con dragones en el Atrato, empezó la contaminación de las aguas. Antes de la minería, el agua era más clara; cuando empezó a ensuciarse las aguas y las ciénagas a sedimentarse. Las ciénagas se han ido rellenando, entonces los nuevos criaderos de los peces se han deteriorado. Ahora no hay criaderos... esta es nuestra mayor preocupación: la muerte del pescado (29 de julio de 2017).

De esta manera, las comunidades se muestran preocupadas por los impactos en los recursos acuáticos por las actividades mineras. En primera instancia, se trata de una percepción compartida por todas las comunidades, que indudablemente lo han discutido y socializado internamente y a nivel del consejo mayor, COCOMACIA. Los mismos pobladores plantean que se trata de una intuición de que es la minería la que está afectando los recursos pesqueros y la calidad de las aguas del Atrato, pero reconocen que bien podría no ser esta la causa, como quedó evidenciado en Beté: "El pescado se agotó por causa de la minería, eso es lo que decimos. Falta saber si es resultado realmente de eso. Aquí en el Atrato pensamos que es la minería (Pescador, Beté, 29 de julio de 2017).

Lo interesante de este reconocimiento de falibilidad de la aproximación local a la problemática, radica que los estudios sostienen que, en efecto, la minería está afectando gravemente las dinámicas hidrológicas, biológicas-ecológicas del río, los ecosistemas y las poblaciones de peces en el Atrato (Lagarejo 2015, IIAP 2008, p. 121, FAO 2002, Fierro 2012, Gutiérrez et al. 2011, p. 126, De la Torre 2015, p. 132, Sánchez et al. 2002, p. 71, Vargas et al. 2010). En este caso, el conocimiento local le lleva una gran ventaja al conocimiento científico. Son las comunidades las que primero perciben los cambios en las dinámicas del agua y del río.

En este sentido, las percepciones de las comunidades sobre el impacto de la minería están dirigidas a estas direcciones. Primero: la relación entre la sedimentación y la disminución de la pesca. Para los pescadores y pobladores, la minería de dragas genera lodos y sedimentos que son transportados aguas abajo, hasta llegar a las ciénagas y caños de cría, crecimiento y reproducción de los peces. La acumulación de los sedimentos en los lechos de ríos y ciénagas reduce la profundidad, e incluso seca las ciénagas, y afecta la calidad del agua, condiciones que son vitales para la existencia de los peces. Así lo plantea un pescador:

La causa es la misma, esa vaina aquí ha afectado bastante: la minería. Desde hace 10-15 años se cogía con atarraya, y era muy abundante el pescado, pero desde que se estableció la minería, entonces el pescado se fue agotando, desde que la maquinaria llegó (San José de la Calle, 28 de julio de 2017).

Segundo: las actividades mineras, los químicos y lodos afectan la calidad del pescado. Para los pobladores, resulta claro que desde la llegada de la minería los pescados se dañan más fácil, tienen mal sabor, color y olor, y afectan negativamente la salud de las personas. Los interlocutores de la localidad de San José de Calle lo mencionan de esta manera: 
Cuando no había minería el pescado duraba, porque no se dañaba tan fácil. Duraba un viaje hasta el mediodía a Quibdó. Ahora después de 4 horas el pescado se daña. El agua está contaminada por la minería y esto afecta la calidad del pescado (Pobladora, San José de la Calle, 28 de julio de 2017). Por la minería, el pescado es contaminado, porque el pescado que uno coge para la familia, entonces esta se enferma y termina con vómito y todo. Entonces uno sabe que es el pescado, que el pescado está contaminado (Pescador, San José de la calle, 28 de julio de 2017).

Y tercero: el impacto de la minería se evidencia en la turbiedad del agua del río. Los pobladores construyen una contraposición entre el presente y la imagen o recuerdo del río en su infancia o juventud. Nunca el río había estado tan sucio, ni bajaba tan turbio. Por el contrario, el agua era limpia y clara. Esta percepción claramente evidencia que se ha naturalizado la imagen de la turbiedad del Atrato, pero que efectivamente este no es el estado normal del río.

Cuando yo era niño, el Atrato era clarito... El río Atrato no aclara ni en verano, es por la minería, desde hace 10 años que no aclara.

El barro del Atrato se asienta en la ciénaga

$\mathrm{y}$ entonces le quita profundidad al agua (Pescador, Buchadó, 28 de julio de 2017).

Ya la FAO desde el año 2002 viene señalando el impacto de la minería en los ecosistemas acuáticos y en las prácticas de pesca, pues básicamente genera la pérdida de la biodiversidad, la cubierta vegetal y favorece el calentamiento global. El agua es uno de los elementos más vulnerables dentro de los ecosistemas, por su estrecha relación con los otros elementos sistémicos (suelo, aire fauna, flora...) motivo por el cual resulta muy afectada ante los impactos y vertimientos ocasionados por las actividades mineras (Fierro 2012). Infortunadamente, no se ha levantado sistemáticamente información que brinde un panorama claro de los alcances y dimensiones de la relación entre minería, agua, pesca en la cuenca del Atrato. Un estudio tal mostraría tal vez una situación mucho más dramática que la planteada por las comunidades y los estudios adelantados hasta el momento, teniendo en cuenta que la explotación minera podría acabar con actividades tradicionales como la pesca, y destruir ecosistemas como las ciénagas y humedales, así como la destrucción de miles de hectáreas de bosque, lo que impactaría en la reducción de cauces y cantidad de aguas de ríos y tributarios de la cuenca del Atrato (Lagarejo 2015).

Infortunadamente, el ecosistema acuático es el que resulta más afectado por las actividades mineras. El agua es utilizada en todas las fases del proceso minero, por lo que se aprovecha de ríos, riachuelos y quebradas tanto como fuentes abastecedoras como de disposición final de los residuos, "de allí que la actividad minera sea la causante de los impactos más severos sobre los cuerpos de agua del municipio del Atrato, que están relacionados con la modificación de la estructura de las redes hídricas locales" (Vargas et al. 2010,p. 28). De esta manera, el recurso hídrico es el que presenta mayores impactos negativos en todos los estudios que se han realizado, lo que se evidencia en las desviaciones de cauces, cambios en las escorrentías, represamientos de cuerpos de aguas lóticas, y una peligrosa sedimentación debido a la acumulación de sólidos provenientes de los lavados y remociones de suelo, lo que disminuye la oferta hídrica y afecta a todos los elementos bióticos y abióticos del ecosistema que están vinculados con la red (Vargas et al. 2010).

Parece que en elChocó las maquinarias mineras siempre están al acecho. El modelo extractivo minero que ha imperado en el Chocó durante más de tres siglos amenaza esta vez trasladarse y consolidarse en la cuenca del Atrato, cuyo peligro 


\section{Bioetnia Volumen 14, 2017}

potencial es el exterminio no sólo de recursos pesqueros, sino también de prácticas tradicionales de producción que legitiman la etnicidad de comunidades negras e indígenas y brindan oportunidades de subsistencia a estas comunidades que han recibido históricamente poca atención de entidades centralizadas o estatales (Domínguez 2015, Leal y Restrepo 2003). Actualmente, todas las especies han disminuido por la contaminación de las aguas, por la modificación de cauces, y el deterioro de áreas inundables (Gutiérrez et al. 2011, p. 135).

A pesar de que en las ciénagas rara vez se reportan actividades mineras in situ, lo cierto es que uno de los mayores impactos negativos que afectan los complejos cenagosos y los humedales de la cuenca media del Atrato, es el vertimiento de materiales procedentes de actividades mineras en zonas medias y altas de las riberas de Atrato y sus afluentes, pero que son transportados hasta estos ecosistemas, tales como:

- Vertimiento de metales pesados (mercurio) (IIAP 2008, p. 121).

- Vertimiento dehidrocarburos(43.000 galones/ año de aceites usados) (Ramírez y Ledezma, 2007: 61)

- Vertimiento de residuos sólidos (400 toneladas/día de sedimentos (IIAP 2011).

Los procesos de deforestación continua, asociados con los cambios de usos de suelo durante la última década, pueden ser los causantes de los cambios químicos del agua, la desestabilización de las paredes de los cauces y alteraciones en las dinámicas hidrológicas, lo que tiene efectos en la productividad y diversidad de los ecosistemas acuáticos del Atrato (Lagarejo 2015, p. 19). También el uso de mercurio en las explotaciones mineras reduce considerablemente la disponibilidad del recurso pesquero (De la Torre 2015, p. 132). En efecto, a nivel internacional, estudios de casos sobre comunidades rurales, pescadores y minería de oro, demuestran la estrecha relación entre la minería y los cambios en abundancia de peces, y cómo la contaminación por mercurio en las prácticas alimentarias está poniendo en peligro la seguridad alimentaria de las comunidades (Laird et al. 2017, Reichelt-Brushett et al. 2017, Niane et al. 2015, Male et al. 2013, Bose-O'Reilly 2016).

Otro elemento importante señalado por las comunidades pesqueras de la cuenca media del Atrato es la preocupación que tienen por las ciénagas, sobre todo por la ciénaga de Los Platillos. Todas las comunidades visitadas plantean la transformación negativa que está sufriendo la ciénaga a causa de la minería. Los pescadores consideran que este ecosistema es el lugar de crecimiento y desarrollo de los peces, por lo que, si esta se encuentra en mal estado, la consecuencia es una disminución o extinción de los peces. Primero, los pobladores (sobre todo de isla de los Palacios y San Alejandro, que están más estrechamente vinculadas con la ciénaga) perciben que la ciénaga se encuentra en un estado grave de sedimentación. Esto ha ocasionado pérdida de profundidad y calidad del agua. Segundo, las actividades antrópicas como la explotación maderera, las palizadas, la minería, y la contaminación del agua, han afectado la cantidad y las especies de la ciénaga; Tercero, el crecimiento de las poblaciones ribereñas, y la mayor demanda de pescado tanto para suplir las necesidades alimentarias de las familias, como para comercializar con otras localidades y regiones, han aumentado la presión pesquera sobre este ecosistema. Cada vez hay más pescadores tratando de capturar pescado en la ciénaga.

Los humedales y las ciénagas son vitales para las comunidades y para los ecosistemas. Para las comunidades, sirve de sustento para prácticas de economías artesanales de subsistencia, como la caza y la pesca. Para los ecosistemas, permite la regulación de aguas y niveles de los ríos y fuentes de biodiversidad (hábitat, especies y tipos genéticos) (Cortés-Duque y Vilardy Quiroga 2014, Correa 2014). Los humedales y ciénagas de la cuenca media del Atrato revisten gran importancia ecológica en Colombia (Lagarejo 2015). 
Bajo este panorama, es posible pensar que la baja presencia, existencia y representatividad de poblaciones de peces en los complejos cenagosos, humedales y ríos, es una respuesta biológica a las graves alteraciones e impactos ambientales ocasionados por actividades antrópicas, como la explotación minera y maderera (Lagarejo 2015, p. 38) y la alta presión pesquera sobre el recurso. Así lo plantea Sánchez et al. (2002, p. 71):

El fenómeno de la reducción de la oferta pesquera es el resultado de la acción combinada del deterioro ambiental en la cuenca y de la presión de captura por talla sobre las especies más importantes.

Cambio en las técnicas: el trasmallo. Para la década de 1990, Román (1991) plantea una serie de aparejos utilizados en las comunidades de pescadores. Se evidencia la presencia del trasmallo desde esa época, pero siempre combinados con el uso de otras técnicas, como la atarraya, el copón, corral, trinchera, tola, fecha y arpón. En ninguna localidad se percibe la presencia preponderante o exclusiva de una técnica o aparejo, sino una combinación de técnicas según la necesidad, la especie y el período (Román 1991, p. 104-6). Por otra parte, es evidente que, a nivel de costos, el trasmallo para esa época resultaba mucho más costosos que cualquier otro aparejo; su poca presencia y su baja demanda, lo hacían más costoso y por tanto, tenía menos presencia en las localidades.

No obstante, en el trabajo de campo se logró comprobar la predominancia casi exclusiva que tiene el trasmallo. Para los pescadores, este aparejo ha significado la posibilidad de realizar mayores capturas, pues la red es más extensa, además que implica poca inversión en tiempo y esfuerzo en su instalación, utilización y retiro. El cambio de técnica, el volcamiento hacia el trasmallo es atribuido por todas las comunidades como un factor también determinante de la presión y reducción de los peces en el Atrato. Para las comunidades, obviamente, se trata de la aceptación de que ellos, como pescadores y pobladores, también generan un impacto significativo sobre los ecosistemas y la población y especies de peces. La mayoría de las comunidades plantean la afirmación según la cual el responsable de la escasez del pescado es el hombre, no sólo porque la minería es una actividad antrópica, sino porque son los mismos pescadores los encargados de impactar los recursos pesqueros. Así lo explicitan los pescadores en dos comunidades distintas:

El principal problema es el hombre, porque hacen mal uso del trasmallo. Es tan pequeña la maya, que ya están cogiendo chopa, que es el pescado más pequeño. Incluso los que cogen chopa, sienten tanta vergüenza que lo esconden y lo venden a hurtadillas porque saben que los demás pescadores incluso recriminan por eso (Pescador, San Alejandro, 27 de julio de 2017).

El hombre, el hombre es el problema: es el tipo de malla con que se está pescado. Acaba con todo, no deja nada. Una solo persona tiene hasta 10 trasmallos. Antes solo eran dos personas, ahora uno solo tiene 10, entonces esto afecta también a la comunidad (Buchadó, 28 de julio de 2017).

Gutiérrez et al. (2011, p. 114) plantean que parece ser que el trasmallo ingresó al Chocó en la década de 1980, traído por poblaciones desplazadas del Golfo de Urabá. Entonces fue tomando forma el uso de artes no selectivas para la captura de peces:

El empleo del trasmallo se difundió rápidamente en el Atrato medio en los últimos diez años, afectando negativamente la ictiofauna debido a su alta eficiencia, poca selectividad y a la interrupción de procesos migratorios de los peces asociados con la reproducción 


\section{Bioetnia Volumen 14, 2017}

o los cambios temporales en la oferta trófica (Sánchez et al. 2002, p. 70).

Han ocurrido varios fenómenos socioeconómicos y ecológicos, vinculados entre sí. Por una parte, el crecimiento de la población y la alta demanda de pescado implicó mayor presión sobre el recurso, y en ese sentido, mayor interés en los pescadores por aumentar la eficacia de las artes de pesca para obtener mejores ganancias. Por otra parte, el volcamiento de la mayoría de los pobladores ribereños del Atrato hacia las actividades de pesca, en detrimento de las otras actividades productivas tradicionales como los cultivos de pancoger. Asimismo, la dedicación casi exclusiva a la pesca durante todo el año. En otras palabras, se presenta el fenómeno según el cual hay muchos pescadores, todo el tiempo (sin períodos de descanso o respetando ciclos de crecimiento, desove o subienda del río) utilizando una técnica no selectiva como el trasmallo.

Además, los procesos de afectación ambiental de la cuenca debido a las explotaciones mineras y madereras, junto con la contaminación de las aguas dañando el recurso pesquero, estuvo acompañado de aumento de la presión sobre el recurso. Menos peces, menos posibilidades de permitir procesos migratorios y ciclos reproductivos, en medio de aumento de pescadores y la cantidad de trasmallos, a la vez que reducían el punto de la malla en la medida que el pescado se percibía más pequeño. De mallas 4.5 y 4 puntos, los pobladores plantean que actualmente están utilizando mallas de 3.5 y 3 , que efectivamente, son tan pequeñas que "recogen todo", grande, pequeño, hembra, alevino...

Los pescadores lo reconocen. Saben que están interrumpiendo los ciclos de migración, crecimiento y reproducción de los peces. No obstante, aumentan la cantidad de trasmallos por pescador (entre 7 y 15), y disminuyen el punto de la malla (a 3.5 y 3). Parece ser un proceso proporcional entre lo biológico y lo tecnológico: si el pescado disminuye en cantidad y tamaño, entonces se aumenta el número de aparejos y se reduce el punto de malla de cada uno para que coja lo más pequeño que pase por este.

Los pescadores plantean que la situación se debe a la necesidad de alimentar a sus familias, y poder comercializar algo para cubrir gastos y deudas de la familia. Si no se pesca, no se come. Entonces la prioridad es conseguir alimento, así sean pescados de mala calidad o inadecuados.

Así mismo, la utilización del trasmallo tiene un gran impacto cultural, pues ha significado el desuso de otras técnicas, conocimientos y aparejos, como la atarraya, el anzuelo y la fecha. Al respecto, los pobladores y pescadores plantean que ya es casi imposible volver a utilizar estos aparejos precisamente porque ya los pescadores se acostumbraron al trasmallo, primero porque implica poco tiempo, y porque resulta más eficiente en la captura de pescados. Y segundo, por las mismas condiciones del río, que al no tener oferta de peces de buen tamaño que puedan ser capturados con la atarraya o anzuelo, hacen que el único aparejo sea el trasmallo.

\section{Conclusiones}

El cambio de técnicas de pesca está relacionado con el contexto ecológico, sociocultural y económico del Chocó. Sin embargo, resulta fundamental prestar atención a esta situación, porque se puede convertir (si no lo es ya) en un círculo vicioso en el que la disminución del recurso pesquero, en calidad, cantidad y tamaño hace que los pescadores utilicen técnicas fuera de norma, más lesivas o no selectivas, lo que ocasiona a su vez mayor presión sobre la población de peces, afectando sus ciclos de vida y migración. Prácticas como el barbasco y el trasmallo, deben tener algún tipo de regulación y control. Tarea en la cual las comunidades étnicas, junto con las autoridades ambientales y administrativa municipales, de mano de la academia, deben buscar caminos viables que permitan 


\section{Entre dragas y trasmallos. WA Cano López}

el sostenimiento de los ecosistemas pero sin que se afecte la seguridad alimentaria de estas comunidades étnicas, ribereñas y pescadoras.

\section{Literatura citada}

Agreda E. 2005. Métodos de investigación etnográfica en minorías étnicas. Tiempo Nuevos. 10 (15): 75-87.

Akimichi T. 2002. Ordenación de los recursos de base comunitaria y orientada a especies: estudio de caso de las pesquerías en pequeña escala de las islas Yaeyama, sudoeste de Japón. En: McGoodwin JR (ed.). Comprender las culturas de las comunidades pesqueras. Clave para la integración pesquera y la seguridad alimentaria. Documento técnico de pesca $\mathrm{N}^{\circ}$ 401. Roma: FAO. Disponible en: http://www.fao.org/docrep/005/ Y1290S/Y1290S00.HTM

Álvarez Lleras J. 1952. Generalidades sobre el Chocó. Boletín de la Sociedad geográfica de Colombia, Vol. $\mathrm{X}, \mathrm{N}^{\circ}$ 2. Disponible en: $\underline{\mathrm{https}: / / \mathrm{www} \cdot \text { sogeocol.edu.co/ }}$ documentos/gen_choco.pdf

Andrade Á(ed.). 2007. Aplicación del enfoque ecosistémico en Latinoamérica. Bogotá: CEM, UICN. Disponible en: http://cmsdata.iucn.org/downloads/423.pdf

Aprile-Gniset J. 1992. La colonización del Atrato. En: La ciudad colombiana: siglo XIX y siglo XX. pp. 262-75. Bogotá: Biblioteca Banco Popular, Fondo de Promoción de la Cultura. 798 pp.

Archivo General de la Nación (AGN). Fondo: Ministerio de Minas, Tomo 9.

Avendaño P. 2006. La pesca artesanal en la discusión sobre la soberanía alimentaria. World Forum of Fish Harvesters and Fish Workers (WWF). Disponible en: http:// www.terre-citoyenne.org/fileadmin/admin/document/ WFF 2006 PA PescaySoberaniaAlimentaria es.pdf

Ayala H. $2003 . \bar{L}$ a valoración ecológica y socioambiental como soportes para la promoción de la minería responsable. Área de Certificación Ecológica y Promoción de Mercados Verdes. Quibdó: Instituto de Investigaciones Ambientales del Pacífico (IIAP).

Ayala H. 2004. La minería en pequeña escala-mape como estrategia de sostenibilidad en territorios mineros de afrocolombianos en el Chocó Biogeográfico. Área de Certificación Ecológica y Promoción de Mercados Verdes. Quibdó: Instituto de Investigaciones Ambientales del Pacífico (IIAP).

Berkes F. 2008. La pesquería de pequeña escala: alternativa al manejo convencional de recursos. pp. 443-59. En: Pinedo D, Soria C (eds.). El manejo de las pesquerías en ríos tropicales de Sudamérica. Ottawa: Mayol Ediciones, Instituto del Bien Común, Centro Internacional de Investigaciones para el Desarrollo (IDRC); 492 pp. Disponible en: https://idl-bnc-idrc.dspacedirect.org/ bitstream/handle/10625/35976/IDL-35976.pdf

Bose-O'Reilly S, Schierl R, Nowak D, Siebert U, William JF, Owi FT, et al. 2016. A preliminary study on health effects in villagers exposed to mercury in a small-scale artisanal gold mining area in Indonesia. Environ Res. 149: 274-81. Disponible en: https://www.ncbi.nlm.nih. gov/pubmed/27174690

Cano WA. 2014. Ríos en disputa: conflictos mineros en Chocó (Colombia) durante el siglo XX. En: Gutiérrez AL, Toro G(eds.). Culturas, ecología humana y ciudadanias. Medellín: Universidad deAntioquia. Disponible en: http://www.academia.edu/16310497/R\%C3\%ADos en Disputa Conflictos Mineros en Choc\%C3\%B3 Colombia durante el siglo xx

Cano WA. 2015. Ríos en disputa: minería, conflictos territoriales y comercio de oro en el Chocó (1907-1939). Tesis Maestría. Medellín: Facultad de Ciencias Sociales y Humanas, Universidad de Antioquia. Disponible en: http:// tesis.udea.edu.co/dspace/bitstream/10495/3532/1/L\%C3\%B3pezcanoW-2015 riosdisputasmineria.pdf

Castrillón H. 1982. Chocó indio. Medellín: Ediciones CPI (Centro Pastoral Indígena); pp. 187-9.

Clay E. 2002. Food security: Concepts and measurement. Paper for FAO Expert Consultation on Trade and Food Security: conceptualising the linkages. Roma, 11-12 July 2002. Chapter 2 . Food Security: conceptualizing and measurement. Disponible en: http://www.fao.org/ docrep/005/y4671e/y4671e06.htm

Contraloría General de la República. 1943. Geografía Económica de Colombia: Chocó. Tomo VI. Bogotá.

Correa JD. 2014. Calidad del agua en humedales del plano de inundación del río Atrato. Revista Ciencias Ambientales y Sostenibilidad. 1 (1): 1-17. Disponible en: https://aprendeenlinea.udea.edu.co/revistas/index. $\mathrm{php} / \mathrm{CAA} /$ article/view/16917

Cortés-Duque J, Vilardy Quiroga SP. 2014. Principios y criterios para la delimitación de humedales continentales: una herramienta para fortalecer la resiliencia y la adaptación al cambio climático en Colombia. Bogotá: Instituto de Investigación de Recursos Biológicos Alexander von Humboldt. Disponible en: http://repository.humboldt.org.co/handle/20.500.11761/31444

Decreto 1745 de 1995. Por el cual se reglamenta el Capítulo III de la Ley 70 de 1993, se adopta el procedimiento para el reconocimiento del derecho a la propiedad colectiva de las Tierras de las Comunidades Negras y se dictan otras disposiciones". Disponible en: https:// www.mininterior.gov.co/la-institucion/normatividad/ decreto-1745-de-1995-2

Defeo O. 2015.Enfoque ecosistémico pesquero. Conceptos 


\section{Bioetnia Volumen 14, 2017}

fundamentales y su aplicación en pesquerías de pequeña escala de América Latina. Documento Técnico N 592. Roma: FAO. Disponible en: https://www.oceandocs. org/bitstream/handle/1834/7413/Defeo $\% 202015 \% 20$ Enfoque $\% 20$ ecosistemico $\% 20$ pesquero $\% 20$ SSF.pdf? sequence $=1$ \&isAllowed $=y$

De la Torre LM. 2015. Las prácticas productivas tradicionales y sus características en el territorio de comunidad negra: caso río Bebará, medio Atrato chocoano. En: Producción más limpia. 10 (2): 127-34. Disponible en: http://repository.lasallista.edu.co:8080/ojs/index. $\mathrm{php} / \mathrm{pl} /$ article/view/903/626

Domínguez MI. 2015. Comunidades negras rurales de Antioquia: discursos de ancestralidad, titulación colectiva y procesos de "aprendizaje" del Estado. Estudios Políticos. 46:101-23. Disponible en: http://aprendeenlinea.udea.edu.co/revistas/index.php/estudiospoliticos/ article/view/19314/20779178

Esquema de Ordenamiento Territorial (EOT), municipio del Medio Atrato. 2005. Documento Diagnóstico 2005-2016. Alianza cívica para el desarrollo del Medio Atrato 2004-2015. Municipio del MedioAtrato, Chocó. Quibdó: Alcaldía Municipal, Instituto de Investigaciones Ambientales del Pacífico, Convenio BID-Plan Pacífico-MAVDT, Gob. Chocó-UTCH-IIAP.

FAO. 1996. Declaración de Roma sobre la Seguridad Alimentaria Mundial y plan de acción. Cumbre Mundial Sobre laAlimentación. Disponible en: http:/www.fao. org/docrep /003/w3613s/w3613s00.htm

FAO, AHP. 2002. Anti-Hunger Programme: Reducing hunger through agriculture and rural development and wideraccess to food, FAO, Roma.

FAO. 2012. El estado mundial de la pesca y la acuicultura. Roma: Departamento de Pesca y Acuicultura de la FAO.Disponible en: http://www.fao.org/3/a-i2727s.pdf

FAO. 2014. Contribución de la pesca y la acuicultura a la seguridad alimentaria y el ingreso familiar en Centroamérica. Panamá: FAO. Disponible en: http:// www.fao.org/3/a-i3757s.pdf

Fierro J. 2012. La política minera en Colombia: la articulación y potenciación de conflictos alrededor de intereses privados. En: Toro Pérez C, Fierra J, Coronado S, Roa T. (eds.): Minería, territorio y conflicto en Colombia. Bogotá: Universidad Nacional de Colombia. Disponible en: http://www.uneditorial.com/mineria-44-territo$\underline{\text { rio-y-conflicto-en-colombia-derecho-ambiental.html }}$

Gutiérrez FdeP, Ortega-Lara A, Sánchez-Garcés GC, Barreto Reyes C. 2011. Diagnóstico de la pesquería en la vertiente del Pacífico. En: Lasso CA, Gutiérrez FdeP, Morales-Betancourt MA, Agudelo E, Ramírez-Gil H, Ajiaco-MartínezRE(eds.).II. Pesquerías continentales de Colombia: cuencas del Magdalena-Cauca, Sinú,
Canalete, Atrato, Orinoco, Amazonas y vertiente del Pacífico. Serie Recursos hidrobiológicos y pesqueros continentales de Colombia. Bogotá: Instituto de Investigación de los Recursos Biológicos Alexander von Humboldt; 304 pp. Disponible en: http://awsassets. panda.org/downloads/pesquerias_cuencas_2.pdf

Gutiérrez FdeP, Rivas-Lara TS, Rincón-López CE. 2011. Diagnóstico de la pesquería en la cuenca del Atrato. En: Lasso CA, Gutiérrez FdeP, Morales-Betancourt MA, Agudelo E, Ramírez-Gil H, Ajiaco-Martínez RE (eds.). II. Pesquerías continentales de Colombia: cuencas del Magdalena-Cauca, Sinú, Canalete, Atrato, Orinoco, Amazonas y vertiente del Pacífico. Serie Recursos hidrobiológicos y pesqueros continentales de Colombia. Bogotá: Instituto de Investigación de los Recursos Biológicos Alexander von Humboldt; 304 pp. Disponible en: http://awsassets.panda.org/downloads/ pesquerias_cuencas_2.pdf

Gajardo C, Ther Ríos F. 2011. Saberes y prácticas pesquero-artesanales: cotidianidades y desarrollo en las Caletas de Guabún y Puñihuil, isla de Chiloé. Chungará. 43 (especial 1): 589-605. Disponible en: https:// scielo.conicyt.cl/scielo.php?script=sci arttext\&pi$\mathrm{d}=\mathrm{S} 0717-73562011000300014$

Heidhues F, Atsain A, Nyangito H, Padilla M, Ghersi G, Le Vallée J-C. 2004. Development Strategies and Food and Nutrition Security in Africa. 2020. Discussion Paper. 50 pp. Disponible en: http://www.ifpri.org/ publication/development-strategies-and-food-and-nutrition-security-africa

Hernández E. 1971. Exploración etnobotánica y su metodología. Reproducido de la edición hecha por el Colegio de Posgraduados, Escuela Nacional de Agricultura(SAG).

Hoffmann O. 2007. Comunidades negras en el Pacífico colombiano. Innovaciones y dinámicas étnicas. Lima: Instituto Francés de Estudios Andinos (IFEA); Quito: Institut de Recherche Pour le Développement (IRD); Quito: Ediciones Abya-Yala; 310 pp. Disponible en: http://digitalrepository.unm.edu/cgi/viewcontent. cgi? article $=1038 \&$ context $=$ abya yala

Instituto de Investigaciones Ambientales del Pacífico (IIAP). 2008. Inventario, priorización y caracterización de las ciénagas del municipio del Medio Atrato, Chocó. Quibdó: IIAP, Ministerio de Medio Ambiente. Disponible en: https://siatpc.iiap.org.co/docs/avances/ ipccienagabete.pdf

Instituto de Investigaciones Ambientales del Pacífico (IIAP). 2011. Valoración integral de los ecosistemas cenagosos del municipio del Medio Atrato, Chocó. Caso Ciénaga Grande de Beté. Quibdó: IIAP; 75 pp. Disponible en: https://siatpc.iiap.org.co/docs/avances/ vibetegrande.pdf 
Entre dragas y trasmallos. WA Cano López

Laird B, Chan HM, Kannan K, Husain A, Al-Amiri H, Dashti $\mathrm{B}$, et al. 2017. Exposure and risk characterization for dietary methylmercury from seafood consumption in Kuwait. Sci TotalEnviron. 607-608:375-80. Disponible en: https://www.ncbi.nlm.nih.gov/pubmed/28697390

Lagarejo MA. 2015. Análisis de los impactos ecológicos generados por la actividad minera sobre los ensamblajes ícticos en complejos cenagosos de Sanceno y Puné en la cuenca media del Atrato. Tesis de grado. Manizales: Facultad de Ciencias Contables Económicas y Administrativas, Universidad de Manizales. Disponible en: http://ridum.umanizales.edu.co:8080/ jspui/bitstream/6789/2471/2/Informe $\% 20$ Final $\% 20$ Tesis.pdf

Lasso, C. A., F. de Paula Gutiérrez, M. A. Morales-Betancourt, E. Agudelo, H. Ramírez-Gil y R. E. Ajiaco-Martínez (Editores). 2011. II. Pesquerías continentales de Colombia: cuencas del Magdalena-Cauca, Sinú, Canalete, Atrato, Orinoco, Amazonas y vertiente del Pacífico. Serie Recursos hidrobiológicos y pesqueros continentales de Colombia. Bogotá: Instituto de Investigación de los Recursos Biológicos Alexander von Humboldt; 304 pp. Disponible en: http://awsassets. panda.org/downloads/pesquerias_cuencas_2.pdf

Leal C, Restrepo E. 2003. Unos bosques sembrados de aserríos: historia de la extracción maderera en el Pacífico colombiano. Medellín: Clío, Colciencias, ICANH, Facultad de Ciencias Humanas y Económicas, Universidad Nacional de Colombia; 100 pp. Disponible en: http://www.ram-wan.net/restrepo/documentos/ bosques-1.pdf

Leal C. 2008. Disputas por tagua y minas: recursos naturales y propiedad territorial en el Pacífico colombiano, 1870-1930. Rev Colomb Antropol. 44 (2): 409-38. Disponible en: http://www.scielo.org.co/scielo.php?pi$\mathrm{d}=\mathrm{S} 0486-65252008000200006 \&$ script $=$ sci_abstract\&tlng=es

Leal C. 2009. La compañia minera Chocó Pacífico y el auge del platino en Colombia, 1897-1930. pp. 150-164. Historia Crítica, edición especial; 362 pp. Disponible en: http://www.scielo.org.co/pdf/rhc/n39s1/n39Ea09.pdf

Lemaitre J. 2011. Derechos enterrados. Comunidades étnicas y campesinas en Colombia, nueve casos de estudio. Bogotá: Universidad de los Andes; 206 pp.

Lemos L, Murillo W, Pabón J. 2012. Los sistemas productivos tradicionales de comunidades negras del Medio Atrato chocoano, su relación con el clima y su vulnerabilidad frente a eventos climáticos extremos. Bioetnia. 9 (1):56-64. Disponible en: http://iiap.org.co/ documents/117f11254fafa526a10ed82d7cac0b2f.pdf

Lozano Garcés R. 1976. Enfoque del cuarto mundo: El Chocó tiene la palabra: 1943 a 1975. Quibdó: Fundación para el Desarrollo de la Cultura del Chocó, Cooperativa Integral de Trabajadores Mineros del Chocó Ltda.

Male YT, Reichelt-Brushett AJ, Pocock M, Nanlohy A. 2013. Recent mercury contamination from artisanal gold mining on Buru Island, Indonesia. Potential future risks to environmental health and food safety. Mar Pollut Bull. 77 (1-2): 428-33. Disponible en: https:// www.ncbi.nlm.nih.gov/pubmed/24074638

Maldonado-Ocampo J, Villa-Navarro F, Ortega-Lara A, Prada-Pedreros S, Jaramillo Villa U, Claro A, et al. 2006. Peces del río Atrato, zona hidrogeográfica del Caribe, Colombia. Biota Colomb. 7 (1): 143-54. Disponible en: http://repository.humboldt.org.co/ bitstream/handle/20.500.11761/32780/170-169-1-PB. pdf? sequence $=1$ \&isAllowed $=y$

Martínez SP. 2013. Hacia una etnografía del Estado: reflexiones a partir de un proceso de titulación colectiva a las comunidades negras del Pacífico colombiano. Universitas Humanística. 75: 157-87. Disponible en: http://revistas.javeriana.edu.co/index.php/univhumanistica/article/viewFile/3843/4800

McGoodwin JR. 2002. Comprender las culturas de las comunidades pesqueras. Clave para la integración pesquera y la seguridad alimentaria. Documento técnico de pesca $\mathrm{N}^{\circ}$ 401. Roma: FAO. Disponible en: http:// www.fao.org/docrep/005/Y1290S/Y1290S00.HTM

Mosquera G. 1992. La colonización del Atrato. En: Aprile Gniset J (ed.). La ciudad colombiana, siglo XIX y siglo XX. Bogotá: Banco Popular, Fondo de Promoción y Cultura; 798 pp. Disponible en: https://books. google.com.co/books/about/La ciudad colombiana. $\underline{h t m l}$ ? id $=8$ B1HAAAAYAAJ\&redir esc $=y$

Niane B, Guédron S, Moritz R, Cosio C, Ngom PM, Deverajan $\mathrm{N}$, et al. 2015. Human exposure to mercury in artisanal small-scale gold mining areas of Kedougou region, Senegal, as a function of occupational activity and fish consumption. Environ Sci Pollut Res Int. 22 (9): 7101-11. Disponible en: https://www.ncbi.nlm. nih.gov/pubmed/25501641

Observatorio de Seguridad Alimentaria y Nutricional de Colombia (OSAN). Componentes y lineamientos para suimplementación. Bogotá: Ministerio de la Protección Social, Instituto Nacional de Salud, Universidad de Antioquia; 230 pp. Disponible en: http://www.osancolombia.gov.co/doc/libroosan.pdf

Oslender U. 2004. Geografías del terror y desplazamiento forzado en el Pacífico colombiano: conceptualizando el problema y buscando respuestas. En: Restrepo E, Rojas A (eds.). Conflicto e (in)visibilidad. Retos en los estudios de la gente negra en Colombia. Popayán: Editorial Universidad del Cauca. Disponible en: http:// publications.iom.int/system/files/pdf/conflicto_e_in- 


\section{Bioetnia Volumen 14, 2017}

visibilidad.pdf

Oslender U. 2008. Comunidades negras y espacio en el Pacífico colombiano. Hacia un giro geográfico en el estudio de los movimientos sociales. Bogotá: Instituto Colombiano de Antroplogía e Historia (ICANH); Popayán: Universidad del Cauca. Disponible en: http:// www.icanh.gov.co/?idcategoria $=6203$

Parra C. 2005. Jurisprudencia relevante para la comunidad afrocolombiana. En: Parra C, Rodríguez GA (eds.). Comunidades étnicas en Colombia. Cultura y jurisprudencia. Bogotá: Universidad del Rosario; 252 pp.

Plan de desarrollo del Medio Atrato 2012-2015.2012. Alcaldía Municipal del Medio Atrato. Una administración de todos y para todos. Medio Atrato: Alcaldía Municipal.

Ramírez-Moreno G, Ledezma-Rentería E. 2007. Efectos de las actividades socioeconómicas (minería y explotación maderera) sobre los bosques del departamento del Chocó. Revista Institucional Universidad Tecnológica del Chocó. 26 (1): 58-65. Disponible en: http:// revistas.utch.edu.co/ojs5/index.php/revinvestigacion/ article/view/467/479

República de Colombia, Ministerio del Interior. 2001. Compendio legislativo para comunidades negras. Bogotá: Dirección General para Comunidades Negras, Minorías Étnicas y Culturales.

República de Colombia. Ley 70 del 27 de agosto de 1993. Por la cual se desarrolla el Artículo transitorio 55 de la Constitución Política. Disponible en: https:// www.mininterior.gov.co/la-institucion/normatividad/ ley-70-de-1993-agosto-27-por-la-cual-se-desarrollael-articulo-transitorio-55-de-la-constitucion-politica

Restrepo E. 2004. Biopolítica y alteridad: dilemas de la etnización de las colombias negras. En: Restrepo E, Rojas A (eds.). Conflicto e (in)visibilidad. Retos en los estudios de la gente negra en Colombia. Popayán: Editorial Universidad del Cauca. Disponible en: http:// publications.iom.int/system/files/pdf/conflicto_e invisibilidad.pdf

Restrepo M. 1992. Poblamiento y estructura social de las comunidades negras del medio Atrato. Trabajo de grado. Bogotá: Departamento de Sociología, Universidad Nacional.

Reichelt-BrushettAS, Stone J, Howe P, Thomas B, Clark M, Male Y, et al. 2017. Geochemistry and mercury contamination in receiving environments of artisanal mining wastes andi dentified concerns forfood safety. Environ Res. 152: 407-18. Disponible en: https://www.sciencedirect.com/science/article/pii/S0013935116302882

Rincón CE, Rivas-Lara TS. 2002. Estudio de peces promisorios en dos ciénagas de la cuenca del río Atrato. Revista Institucional Universidad Tecnológica del Chocó. 8: 24-6.
Rivas-Lara TS, Gómez-Vanega HD. 2017. Algunos aspectos biológicos y pesqueros de Caquetaia kraussi (Steindachner, 1878) en la cuenca media y baja del río Atrato, Chocó. Rev Biodivers Neotrop. 7 (1): 14-21. Disponible en: http://revistas.utch.edu.co/ojs5/index. $\mathrm{php/Bioneotropical/article/view/551/pdf} 20$

Rodríguez GA. 2005. Comunidades afrocolombianas. En: Parra C, Rodríguez GA (eds.). Comunidades étnicas en Colombia. Cultura y jurisprudencia. Bogotá: Universidad del Rosario; 252 pp.

Román C. 1991. Estudio de algunos aspectos sociales de la pesca en la cuenca medio del río Atrato. Revista de Ciencias. Disponible en: http://bibliotecadigital.univalle.edu.co/bitstream/10893/4933/1/ESTUDIO $\% 20$ DE\%20ALGUNOS.pdf

Sánchez JI, Sequeira D, Palacio J. 2002. Ictiofauna y actividad pesquera en la microcuenca del río Chajeradó, Atrato medio (Colombia). Actual Biol. 24 (77): 67-71. Disponible en: https://aprendeenlinea.udea.edu.co/revistas/index.php/actbio/article/view/329540/20785971

Sandoval-Moreno A, Hernández-García A. 2013. Cambios socioambientales y crisis de los pescadores en el lago de Chapala, en México. Ambiente y Desarrollo. 17 (32): 13-27. Disponible en: https://webcache.googleusercontent.com/search? $\mathrm{q}=$ cache: $1 \mathrm{~s} 31 \mathrm{KeCHfrEJ}:$ https:// dialnet.unirioja.es/descarga/articulo/4468363.pdf $+\& c-$ $\mathrm{d}=1 \& \mathrm{hl}=\mathrm{es} \& \mathrm{ct}=\mathrm{clnk} \& \mathrm{gl}=\mathrm{co}$

Stoffle R. 2002. Cuando el pescado es agua: seguridad alimentaria y pescado en una comunidad costera de la República Dominicana. En: McGoodwin JR (ed.). Comprender las culturas de las comunidades pesqueras. Clave para la integración pesquera y la seguridad alimentaria. Documento técnico de pesca N 401. Roma: FAO. Disponible en: http://www.fao.org/docrep/005/ Y1290S/Y1290S00.HTM

Valderrama M. 2011. Prólogo. II. Pesquerías continentales de Colombia: cuencas del Magdalena-Cauca, Sinú, Canalete, Atrato, Orinoco, Amazonas y vertiente del Pacífico. Serie Recursos hidrobiológicos y pesqueros continentales de Colombia. Bogotá: Instituto de Investigación de los Recursos Biológicos Alexander von Humboldt; 304 pp. Disponible en: http://awsassets. panda.org/downloads/pesquerias_cuencas_2.pdf

Vargas L, Quesada Z, Ramírez G, Valoyes Z. 2010. Diagnóstico ambiental de las áreas degradadas por la actividad minera en el municipio de Atrato, Chocó. Bioetnia. 广 (1): 23-37. Disponible en: http://iiap.org.co/documents/ d0bd48b33419c17ee30617d63c1b56e7.pdf

West RC. 1972. La minería de aluvión en Colombia durante el período colonial. Bogotá, Imprenta Nacional. 